\title{
Changes of High-Purity Insoluble Fiber from Soybean Dregs (Okara) after Being Fermented by Colonic Flora and Its Adsorption Capacity
}

\author{
Bo Lyu ${ }^{1,2,+} \mathbb{D}$, Yi Wang $2,3,+$, Xin Zhang ${ }^{1,2}$, Yuxi Chen ${ }^{2,3}$, Hongling Fu ${ }^{2,3}$, Tong Liu 4 , Jianyu Hao ${ }^{5}$, Yang Li ${ }^{1,2}$, \\ Hansong $\mathrm{Yu}^{2,3, *}$ and Lianzhou Jiang ${ }^{1,2, *}$ \\ 1 College of Food Science, Northeast Agricultural University, Harbin 150030, China; \\ michael_lvbo@163.com (B.L.); 18249032236@163.com (X.Z.); yangli@neau.edu.cn (Y.L.) \\ 2 Soybean Research \& Development Center, Division of Soybean Processing, Chinese Agricultural \\ Research System, Changchun 130118, China; Wangyi284419@163.com (Y.W.); \\ chenyuxi19970624@163.com (Y.C.); 15764381475@163.com (H.F.) \\ 3 College of Food Science and Engineering, Jilin Agricultural University, Changchun 130118, China \\ 4 College of Food Science and Engineering, Changchun University, Changchun 130118, China; liut@ccu.edu.cn \\ 5 School of Food and Biotechnology, Changchun Vocational Institute of Technology, Changchun 130118, China; \\ haojianyu55@126.com \\ * Correspondence: yuhansong@jlau.edu.cn (H.Y.); jlzname@neau.edu.cn (L.J.); Tel.: +86-133-3176-0468 (H.Y.); \\ +86-139-0465-1669 (L.J.) \\ + These authors contributed equally to this work.
}

check for

updates

Citation: Lyu, B.; Wang, Y.; Zhang, X.; Chen, Y.; Fu, H.; Liu, T.; Hao, J.; Li, Y.; Yu, H.; Jiang, L. Changes of High-Purity Insoluble Fiber from Soybean Dregs (Okara) after Being Fermented by Colonic Flora and Its Adsorption Capacity. Foods 2021, 10, 2485. https://doi.org/10.3390/ foods10102485

Academic Editor: Adriana S. Franca

Received: 10 September 2021

Accepted: 14 October 2021

Published: 17 October 2021

Publisher's Note: MDPI stays neutral with regard to jurisdictional claims in published maps and institutional affiliations.

Copyright: (c) 2021 by the authors. Licensee MDPI, Basel, Switzerland. This article is an open access article distributed under the terms and conditions of the Creative Commons Attribution (CC BY) license (https:/ / creativecommons.org/licenses/by/ $4.0 /)$.

\begin{abstract}
In order to explore the changes and properties of high-purity insoluble dietary fiber from okara (HPIDF) after entering the colon and be fermented by colonic flora, fermented high-purity insoluble dietary fiber (F-HPIDF) was obtained by simulated fermentation in vitro by HPIDF and colonic flora from C57BL/ 6 mice. For exploring the differences of HPIDF and F-HPIDF, the changes of structure (SEM. FTIR, XRD, particle size, specific surface area, monosaccharide composition) and adsorption properties (water, oil, heavy metal irons, harmful substances) of HPIDF/F-HPIDF were explored. The results showed that F-HPIDF had a higher water-holding capacity $(19.17 \mathrm{~g} / \mathrm{g})$, water-swelling capacity $(24.83 \mathrm{~mL} / \mathrm{g})$, heavy metals-adsorption capacity $\left(\mathrm{Cd}^{2+}: 1.82 \mu \mathrm{mol} / \mathrm{g} ; \mathrm{Pb}^{2+}\right.$ : $1.91 \mu \mathrm{mol} / \mathrm{g} ; \mathrm{Zn}^{2+}: 1.30 \mu \mathrm{mol} / \mathrm{g} ; \mathrm{Cu}^{2+}: 0.68 \mu \mathrm{mol} / \mathrm{g}$ ), and harmful substances-adsorption capacity (GAC: $0.23 \mathrm{~g} / \mathrm{g}$; CAC: $14.80 \mathrm{mg} / \mathrm{g}$; SCAC: $0.49 \mathrm{~g} / \mathrm{g}$ ) than HPIDF due to the changes of structure caused by fermentation. In addition, with the fermentation of HPIDF, some beneficial substances were produced, which might be potential intestinal prebiotics. The study of F-HPIDF strengthens the speculation that HPIDF may have potential bioactivities after entering the colon, which proved that okara-HPIDF may have potential functionality.
\end{abstract}

Keywords: soybean residue; insoluble dietary fiber; gut microbiota; fermentation in vitro; colon health

\section{Introduction}

The functionality of insoluble dietary fiber (IDF) has been gradually accepted by consumers [1-3]. Especially for intestinal health, IDF may have unique physiological activities [4-6]. As a kind of material that can improve intestinal health, IDF had been gradually developed as a kind of functional food material. However, recent studies have shown that some kinds of IDF are not necessarily beneficial to intestinal health [7-9], which may be due to the complex fermentation mode of IDF after entering the colon. It had been proved that roughly ten subtypes of dietary fibers described to date, categorized as soluble or insoluble, with varying chemical structures, and large differences in their fermentation profiles [10]. This means that the changes of gut microbiota and colonic environment are complex. Therefore, the changes of different kinds of IDF in the colon become worthy to study. 
Okara (Soybean dregs), the main by-product during traditional soybean products processing and the production of soybean protein isolate (SPI), had caused huge environmental pollution and waste of resources [11], which includes a large amount of dietary fiber (DF). Okara-DF had been proved to be functional, such as decreased content of blood glucose [12], protected the intestine [13], used as a food raw material ingredient [14], etc. However, different from soluble dietary fiber (SDF), the application of Okara-IDF had a core problem-IDF was difficult to purify. The traditional processing method of IDF is often accompanied by a large amount of protein and soluble fiber as remains. It is difficult to evaluate the functionality of one component in the mixture, as while as caused a disturbance, In addition, okara was difficult to dry because of its unique structure [15]. For these reasons, the usage or value-increment of Okara-IDF as a material of functional food was restricted.

To solve the problem, we prepared high purity insoluble dietary fiber from okara (Okara-HPIDF) by enzymatic method, which purity could exceed $90 \%$ [16], and proved that it had potential bioactivities. Meanwhile, we proved that Okara-HPIDF had certain functions, such as improving lipid metabolism and so on $[17,18]$. In the process of studying its relationship with the changes of the colonic environment, we found that Okara-HPIDF could significantly change the composition of colonic flora [18]. This means that OkaraHPIDF was fully fermented by microorganisms in the colon, which may lead to changes in structure, composition, functionality, and even bioactivities of Okara-HPIDF. The above changes had not been studied, because we used germ-free simulated digestive fluid (SGF) in the previous study [16].

In this way, this study aimed to explore the changes after Okara-HPIDF enters the colon, while being fermented by colonic microorganisms. In this work, we were committed to treating Okara-HPIDF by simulated intestinal fluid (SIF) with colonic microorganisms and digestive enzymes, to look for the changes of Okara-HPIDF after fermentation. The structure, monosaccharide composition, and physicochemical properties before and after fermentation were studied, and a more accurate model of simulated fermentation in vitro of Okara-HPIDF was established. This study is a supplement to our team's previous research, to explore the changes and properties of HPIDF after entering the colon and be fermented by colonic flora, which will improve our evaluation system for the potential biological activity of HPIDF and provide a theoretical basis for improving the biological activity of HPIDF. This work will also be the basic theory to functional research of Okara-HPIDF, which is also the core data of the relationship between the intake of Okara-HPIDF and colon health.

\section{Materials and Methods}

\subsection{Preparation of Okara-HPIDF}

Low purity dietary fiber from okara (okara-LPDF) was purchased from Shandong Sinoglory Health Food Co., Ltd., Liaocheng, China. After identification, its main components include: dietary fiber $\geq 60 \%$, protein $\leq 26 \%$, moisture $\leq 10 \%$, ash $\leq 6 \%$. HPIDF from okara was prepared by complex enzymatic method of LPDF [17]. The purity of HPIDF was $91.25 \%$ (according to the enzymatic-gravimetric method described in Chinese national standard GB 5009.88-2014).

\subsection{The Fermentation of Okara-HPIDF}

The preparation method of simulated intestinal fluid (SIF) was used following the United States Pharmacopeia (USP) [19]. Enzyme-free SIF was prepared in a sterile environment and sterilized at $121^{\circ} \mathrm{C}$ for $20 \mathrm{~min}$.

The collection method of feces was similar to the previous study [16] with minor changes: $10 \mathrm{~g}$ of feces was collected from C57BL/ 6 female mice (Beijing Vital River Laboratory Animal Technology Co. Ltd., Beijing, China), which was dissolved in $50 \mathrm{~mL}$ phosphate buffer solution $(0.1 \mathrm{~mol} / \mathrm{L}, \mathrm{pH}=6.5)$. After complete mixing, the residue was removed 
via filtration with four layers of gauze. The suspension was stored at $-20{ }^{\circ} \mathrm{C}$ in a sterile centrifuge (finished in $1 \mathrm{~h}$ ).

After the preparation of SIF and the extraction of colonic microorganisms, they were mixed in a ratio of 7:2 $(v / v)$. The simulated intestinal fluid with a colonic microorganism (SIF-CM) was used as the fermentation environment for HPIDF. The SIF-CM solution was prepared just before use.

\subsection{Bacterial $16 S$ rDNA Sequencing}

Feces collected in 2.2 were used for $16 \mathrm{~S}$ rDNA sequencing. DNA extraction from feces was carried out using the QIAamp ${ }^{\circledR}$ DNA Stool Mini Kit (QIAGEN, Germany) according to the manufacturer's instructions. The quality of isolated DNA was evaluated on agarose gel electrophoresis and then DNA concentration was precisely measured using a NanoDrop NC2000 spectrophotometer (Thermo Fisher, Waltham, MA, USA).

The V3-V4 region of the 16S rRNA gene was amplified from the purified DNA of each sample. The primers used for the PCR amplification are as follows: the forward primer $515 \mathrm{~F}\left(5^{\prime}\right.$-ACTCCTACGGGAGGCAGCA-3') and the reverse primer 907R (5'-GGACTACHVGGGTWTCTAAT-3'). The concentrations of PCR products were measured by the Quant-iT PicoGreen dsDNA Assay Kit (Invitrogen, Carlsbad, CA, USA). Afterward, all PCR products were pooled in equal amounts, and paired-end sequencing was performed using the Illumina MiSeq platform operated by Shanghai Personal Biotechnology Co., Ltd. (Shanghai, China).

\subsection{Simulated Fermentation of Okara-HPIDF In Vitro}

After mixing SIF-CM and HPIDF (9:1, $v / m)$ under sterile conditions, the samples were cultured under anaerobic conditions at $37^{\circ} \mathrm{C}$ for $16 \mathrm{~h}$. After fermentation, the samples were filtered, the IDF was taken to determine the contents of the composition of monosaccharide after sterilization. The fermented-HPIDF (F-HPIDF) was used for the follow-up experiments after sterilization and freeze-drying.

\subsection{Structure of Okara-HPIDF before/after Fermentation}

\subsubsection{Scanning Electron Microscopy (SEM)}

Merlin Compact scanning electron microscope (SEM; Carl Zeiss Jena GmbH, Jena, Germany) was used to observed the microstructure of HPIDF/F-HPIDF after the spray gold treatment. The scanning images were captured at accelerating voltages of $5.00 \mathrm{kV}$. All images were recorded at magnifications of $300 \times$ (low magnification) and $3000 \times$ (high magnification).

\subsubsection{Fourier Infrared Spectrum (FT-IR)}

The polysaccharide functional group composition of HPIDF/F-HPIDF were performed using a Nicolet iS5 FT-IR spectrometer (Thermo Fisher, Waltham, MA, USA). The spectra were read over the range of $4000-400 \mathrm{~cm}^{-1}$ with a resolution of $4 \mathrm{~cm}^{-1}$ after the samples were mixed with $\operatorname{KBr}(1: 100, w / w)$

\subsubsection{X-ray Diffraction (XRD)}

X-ray diffraction (XRD) analysis of the HPIDF/F-HPIDF was conducted according to the previous method [20], with some slight modifications. The diffraction patterns were recorded using a Rigaku Ultima IV (X-ray, Rigaku Corporation, Tokyo, Japan) operating at a voltage of $40 \mathrm{kV}$, an incident current of $40 \mathrm{~mA}$, an anti-diffusion slit of 2/3, with Cu-Ka radiation $(1 \mu=0.154 \mathrm{~nm})$, and a scan speed of $1 \pi / \mathrm{min}$ in the range of diffraction angle from 10 to $80^{\circ}$. 


\subsubsection{Particle Size and Specific Surface Area}

The BT-9300HT laser particle sizer (Bettersize Instruments Ltd., Dandong, China) was used to analyze the particle size and specific surface area of HPIDF/F-HPIDF in which the concentration of the suspension is $4 \%(\mathrm{~m} / \mathrm{v})$.

\subsection{Monosaccharide Composition of Okara-HPIDF before/after Fermentation and the Hydrolyzed}

The monosaccharide compositions of HPIDF/F-HPIDF referred to the methods of the preliminary study [16]. The monosaccharide composition of the hydrolyzed was analyzed after freeze-drying by PMP pre-column derivatization and LC-10ATvp \& SPD-10AVD HPLC system (Shimadzu, Tokyo, Japan) [21].

\subsection{Adsorption Capacity in the Colon of Okara-HPIDF before/after Fermentation}

\subsubsection{Basic Characteristics of HPIDF/F-HPIDF}

We chose water-holding capacity (WHC), water-swelling capacity (WSC), and oilholding capacity $(\mathrm{OHC})$ as the basic characteristics of HPIDF/F-HPIDF. The determination was described by Zhang et al. [22] with minor changes. Briefly, water-holding capacity (WHC): $1.00 \mathrm{~g}$ sample (M1) and $20 \mathrm{~mL}$ of water were mixed in a dry centrifuge tube (M0). The sample was kept at RT for $24 \mathrm{~h}$ and centrifuged at $4000 \mathrm{rpm}$ for $20 \mathrm{~min}$. The supernatant was removed, and the weight (M2) was measured.

$$
\mathrm{WHC}(\mathrm{g} / \mathrm{g})=(\mathrm{M} 2-\mathrm{M} 0) / \mathrm{M} 1 * 100 \%
$$

Water-swelling capacity (WSC): $0.10 \mathrm{~g}$ (M0) sample was taken into the calibration tube (V0), $10 \mathrm{~mL}$ water was added and let to stand for $24 \mathrm{~h}$, and the volume (V1) was recorded.

$$
\mathrm{WSC}(\mathrm{mL} / \mathrm{g})=(\mathrm{V} 1-\mathrm{V} 0) / \mathrm{M} 0
$$

Oil-holding capacity (OHC): $1.00 \mathrm{~g}$ sample (M1) and $20 \mathrm{~mL}$ of oil (soybean oil/lard) were mixed in a dry centrifuge tube (M0). The sample was kept at RT for $18 \mathrm{~h}$ and centrifuged at $4000 \mathrm{rpm}$ for $20 \mathrm{~min}$. The supernatant was removed, and the weight (M2) was measured.

$$
\mathrm{OHC}(\mathrm{g} / \mathrm{g})=(\mathrm{M} 2-\mathrm{M} 0) / \mathrm{M} 1 * 100 \%
$$

Soybean oil represents unsaturated oil, and lard represents saturated oil.

\subsubsection{Heavy Metals-Adsorption Capacity (HMAC)}

HMAC was measured by the methods of the previous study [16] with minor changes. The $50 \mu \mathrm{g} / \mathrm{mL}$ standard solution of $\mathrm{Pb}^{2+}\left(\mathrm{Pb}\left(\mathrm{NO}_{3}\right)_{2}\right), \mathrm{Zn}^{2+}\left(\mathrm{Zn}\left(\mathrm{NO}_{3}\right)_{2}\right), \mathrm{Cu}^{2+}\left(\mathrm{Cu}\left(\mathrm{NO}_{3}\right)_{2}\right)$, and $\mathrm{Cd}^{2+}\left(\mathrm{Cd}\left(\mathrm{NO}_{3}\right)_{2}\right)$ were prepared as the initial concentration to determine the HMAC of HPIDF/F-HPIDF. Total of $10 \mathrm{~mL}$ of four kinds of standard solutions were mixed with $0.1 \mathrm{~g}$ HPIDF (500 $\mu \mathrm{g}$ of metal ions in the system) separately, and stirred at $37^{\circ} \mathrm{C}$ for $14 \mathrm{~h}$ before centrifuging at $4000 \mathrm{rpm}$ for $20 \mathrm{~min}$. The 240 Duo GFAAS (Agilent, Lexington, MA, USA) was used to detect the content of $\mathrm{Pb}^{2+}, \mathrm{Zn}^{2+}, \mathrm{Cu}^{2+}$, and $\mathrm{Cd}^{2+}$ in the supernatant according to the preinstalled methods of the workstation.

\subsubsection{Potentially Harmful Substances-Adsorption Capacity}

Glucose-adsorption capacity (GAC), cholesterol-adsorption capacity (CAC), sodium cholate-adsorption capacity (SCAC), acrylamide-adsorption capacity (AAC), and nitriteadsorption capacity (NAC) were selected as the measurement indicators of potentially harmful substances-adsorption capacity. The details are as follows:

1. GAC $0.1 \mathrm{~g}$ HPIDF/F-HPIDF, mixed with $10 \mathrm{~mL} 100 \mathrm{mmol} / \mathrm{L}$ glucose solution at $37^{\circ} \mathrm{C}$ for $16 \mathrm{~h}$, centrifuged at $4000 \mathrm{rpm}$ for $20 \mathrm{~min}$, and the supernatant was taken to determine the glucose concentration using a glucose kit (hexokinase method, A154-21, Nanjing Jiancheng Bioengineering Institute). 
2. CAC $1 \mathrm{mg} / \mathrm{mL}$ cholesterol in ethanol solution was prepared. About $0.2 \mathrm{~g}$ HPIDF/FHPIDF was mixed in $10 \mathrm{~mL}$ cholesterol solution. The adsorption and centrifugation conditions were the same as the above. Total cholesterol assay kit (A111-1-1, Nanjing Jiancheng Bioengineering Institute) was used to determine the cholesterol content in the supernatant.

3. SCAC $0.1 \mathrm{~g}$ HPIDF/F-HPIDF was mixed with $10 \mathrm{~mL}$ sodium cholate standard solution $(0.2 \mathrm{~g}$ sodium cholate $+15 \mathrm{mmol} / \mathrm{L} \mathrm{NaCl}$ aq $100 \mathrm{~mL})$. The adsorption and centrifugation conditions were the same as 2.7.3-1. Furfural-sulfuric acid process [23] was used to determine the content of sodium cholate in the supernatant.

4. AAC $0.5 \mathrm{~g}$ HPIDF/F-HPIDF was mixed with $50 \mathrm{~mL} 15 \mathrm{mmol} / \mathrm{L}$ acrylamide solution. The adsorption and centrifugation conditions were the same as 2.7.3-1. HPLC was used to determine the concentration of acrylamide in the supernatant according to the method described in GB 5009.204-2014 by 1260 HPLC (Agilent, Lexington, MA, USA).

5. NAC $0.5 \mathrm{~g}$ HPIDF/F-HPIDF was mixed with $50 \mathrm{~mL} 100 \mathrm{mmol} / \mathrm{L}$ nitrite (Sodium nitrite) solution. The adsorption and centrifugation conditions were the same as the above. Ultraviolet spectrophotometry method (described in GB 5009.23-2010) was used to determine the concentration of sodium nitrite in the supernatant.

\subsection{Statistical Analysis}

The measurements of all samples should be repeated for at least three times and the results were expressed as the mean \pm standard deviations $(\bar{x} \pm \mathrm{SD})$. ANOVA with Duncan's test and Tukey's test was used to compare the data for the differences, $p<0.05$ represented significant differences.MS Word and GraphPad Prism 6 (GraphPad Software Inc., San Diego, CA, USA) were used to organize the data, draw the graphs and tables.

\section{Results and Discussion}

\subsection{The Gut Microbiota Structure in the Feces from C57BL/6 Mice}

The microbiota structure in the colon was analyzed by high-throughput sequencing spanning the $16 \mathrm{~S}$ rDNA V3-V4 hypervariable region and shown in Figure 1. At the phylum level, Firmicutes (55.17\%) and Bacteroidetes (43.62\%) were abundant. As for the genus level, Lactobacillus (14.71\%) accounted for the highest abundance of recognizable conventional microorganisms, which was consistent with the microbial composition of normal C57BL/ 6 mice feces [24]. C57BL/ 6 mice were used as a suitable animal model to evaluate dietary fiber and colon health. In other studies of HPIDF, we also chose this animal model. Therefore, we selected their feces for gut microbiota isolation and fermented HPIDF in vitro.

\subsection{The Structural Changes of HPIDF after Being Fermented}

\subsubsection{Scanning Electron Micrograph (SEM)}

The microstructure of HPIDF/F-HPIDF at 300 times and 3000 times was shown in Figure 2. It can be observed that whether at low magnification or high, F-HPIDF showed a few differences compared to HPIDF. At low magnification (Figure 2a,c), the state of a single dietary fiber particle of F-HPIDF was richer in spatial structure and less smooth than that of HPIDF. In addition, the edge of F-HPIDF's particle was smoother and the tearing feeling was lower than that of HPIDF. At high magnification (Figure 2b,d), the flatness of HPIDF was much higher than that of F-HPIDF, whose structure was chaotic and uneven. This might indicate that F-HPIDF had a higher specific surface area than HPIDF and may be attributed to the removal of some saccharide structure (monosaccharide, etc.,) and the fracture of fiber structure of HPIDF during fermentation. Therefore, we can speculate that some adsorption properties of F-HPIDF should be better than HPIDF because its specific surface area increased (Premise: no functional groups with adsorption properties were removed). This assumption needs to be verified by the following experiments. 
a

- Firmicutes

- Bacteroidetes

- Verrucomicrobia

$\square$ Proteobacteria

- Deferribacteres

- Tenericutes

- Actinobacteria

- Others

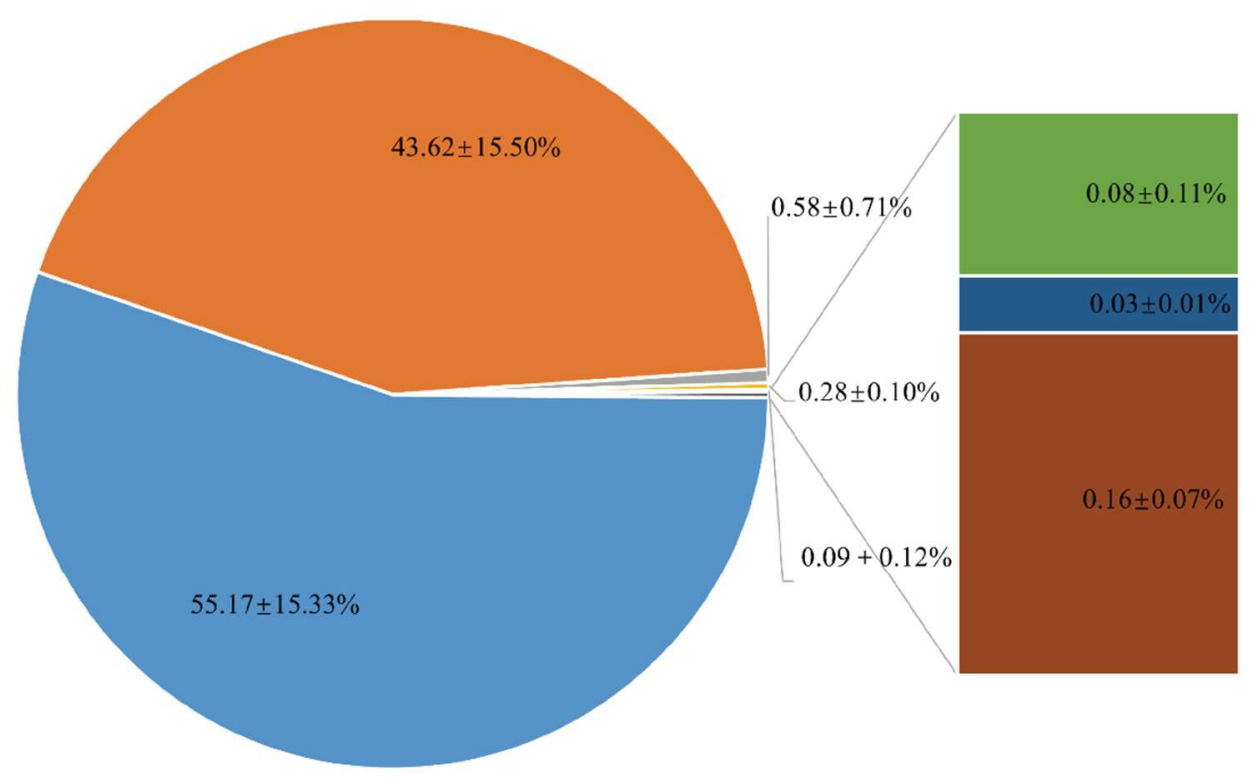

b

- Lactobacillus

- Bacteroides

- Oscillospira

- Akkermansia

- [Ruminococcus]

- Alistipes

- Coprococcus

- Prevotella

- [Prevotella]

- Ruminococcus

- Others

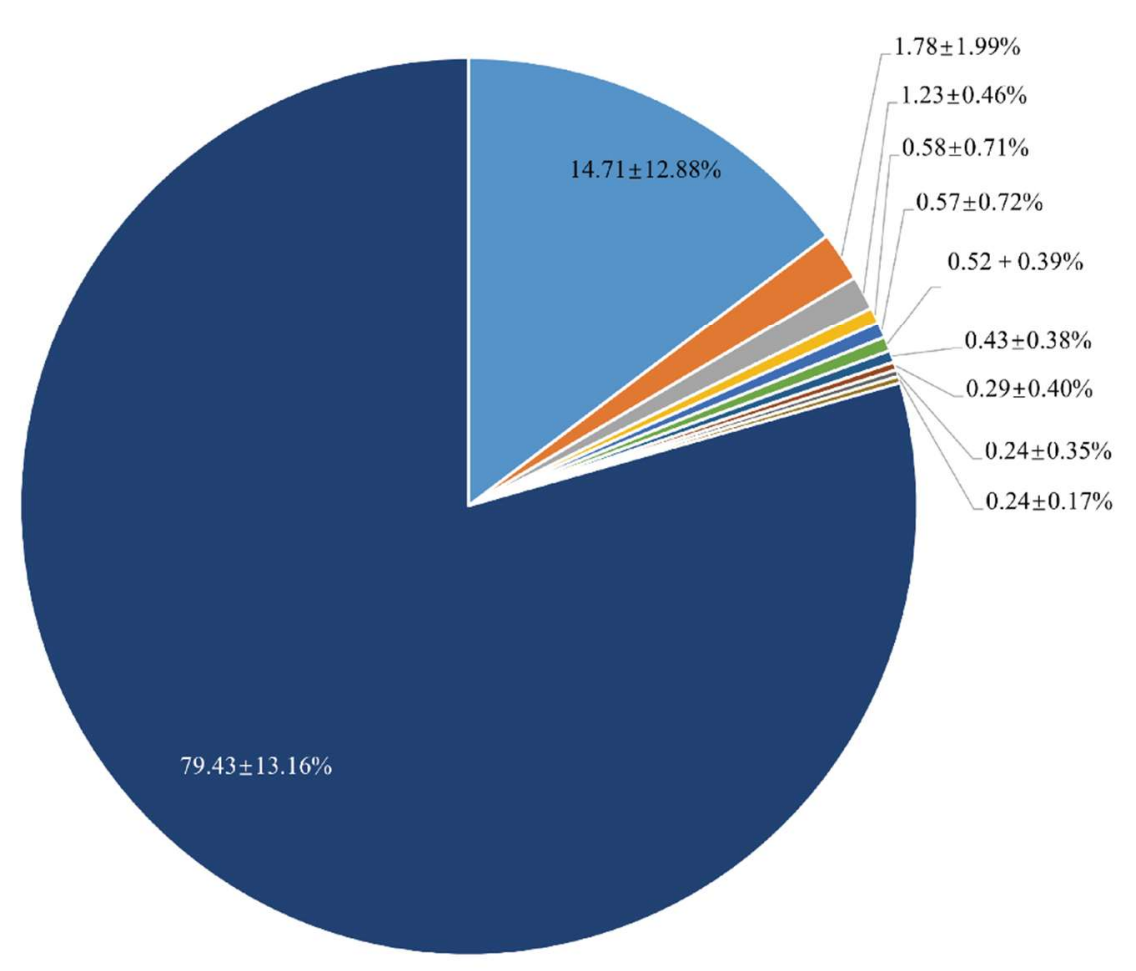

Figure 1. The gut microbiota structure in the feces from C57BL/6 mice. (a: Phylum Level; b: Genus Level). 

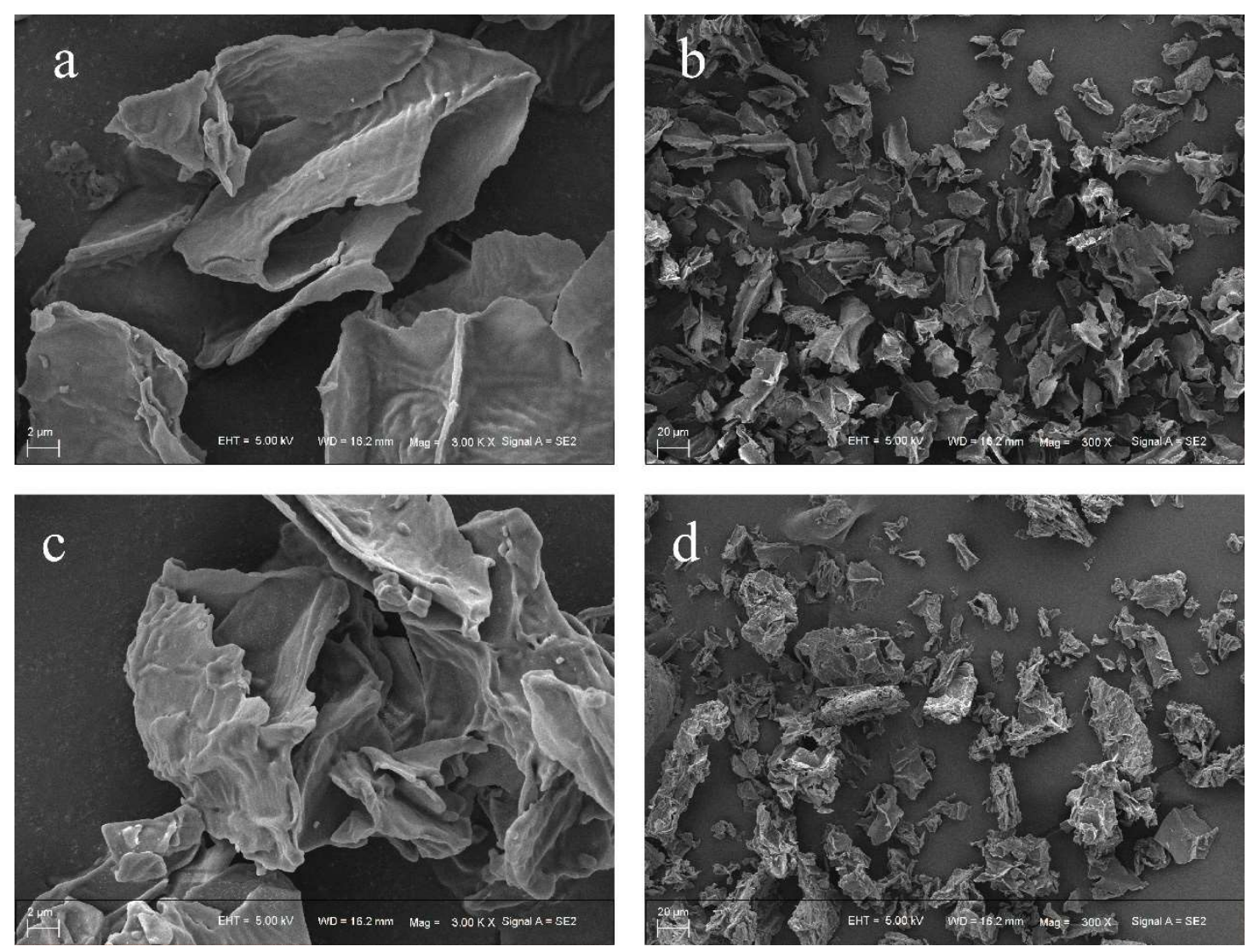

Figure 2. Scanning electron micrograph (SEM) of HPIDF/F-HPIDF. (a: HPIDF at high magnification; b: HPIDF at low magnification; c: F-HPIDF at high magnification; d: F-HPIDF at low magnification).

\subsubsection{X-ray Diffraction (XRD)}

The XRD analysis of HPIDF/F-HPIDF is shown in Figure 3. It could be seen from the XRD spectra that, whether HPIDF or F-HPIDF, there was just one obvious crystal diffraction peak at $2 \theta=22^{\circ}$, which was a characteristic XRD curve of hemicellulose [25]. Meanwhile, there was little difference between HPIDF and F-HPIDF, which proved our previous speculation that the cellulose content in HPIDF is less [16]. XRD spectra showed the same results. In short, the fermentation process did not change the crystal structure of HPIDF.

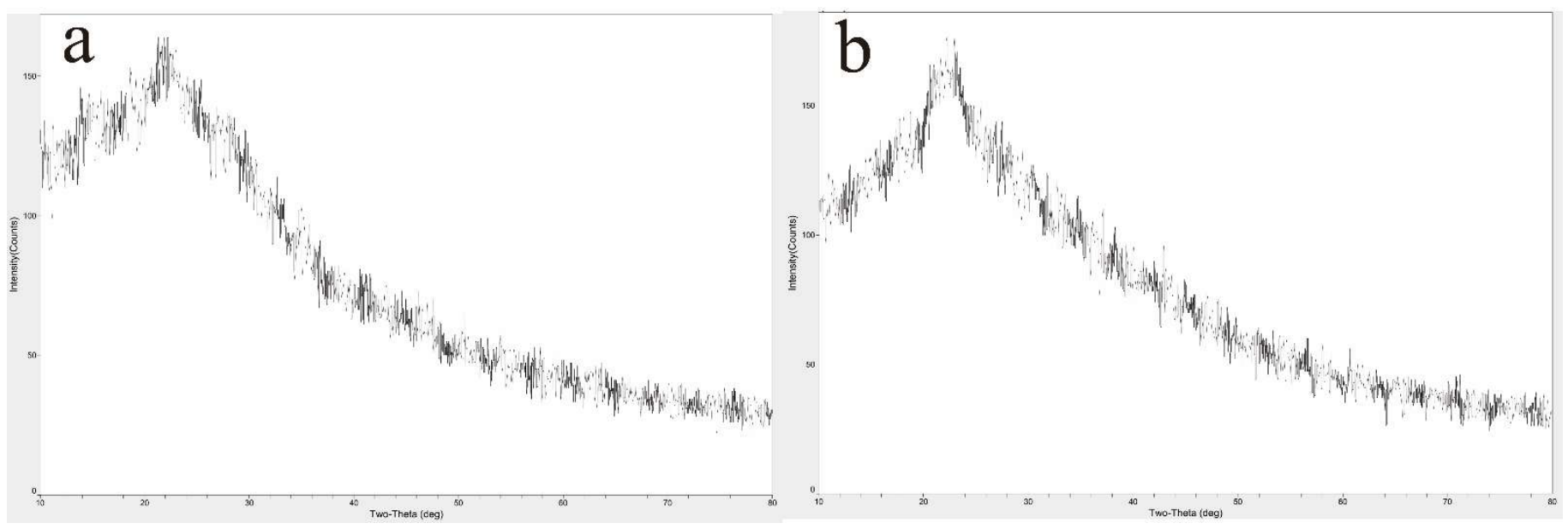

Figure 3. X-ray diffraction (XRD) of HPIDF/F-HPIDF. (a: HPIDF; b: F-HPIDF). 


\subsubsection{Fourier Transform Infrared Spectroscopy (FT-IR)}

The FR-IR spectrum of HPIDF/F-HPIDF is shown in Figure 4. At $3353 \mathrm{~cm}^{-1}, 2932 \mathrm{~cm}^{-1}$, $1737 \mathrm{~cm}^{-1}, 1626 \mathrm{~cm}^{-1}, 1418 \mathrm{~cm}^{-1}, 1374 \mathrm{~cm}^{-1}, 1248 \mathrm{~cm}^{-1}, 1057 \mathrm{~cm}^{-1}, 706 \mathrm{~cm}^{-1}, 623 \mathrm{~cm}^{-1}$, and $532 \mathrm{~cm}^{-1}$, both HPIDF/F-HPIDF showed significant absorption peak, which represented the composition of their polysaccharide functional groups. Actually, although HPIDF and F-HPIDF showed some differences in peak height, no differences in peak location were observed. In contrast with other studies [26-28], these absorption peaks represented O-H group in cellulose or hemicellulose, $\mathrm{C}-\mathrm{H}$ stretching of $-\mathrm{CH}_{3}$ or $=\mathrm{CH}_{2}$ on carboxymethyl and methylene, oxygen (CO-OR) stretching vibration in hemicelluloses, C-O stretching vibration in the guaiacyl unit of lignin, glycuronic acid, etc. The other small peaks were not different from the previous study [16].

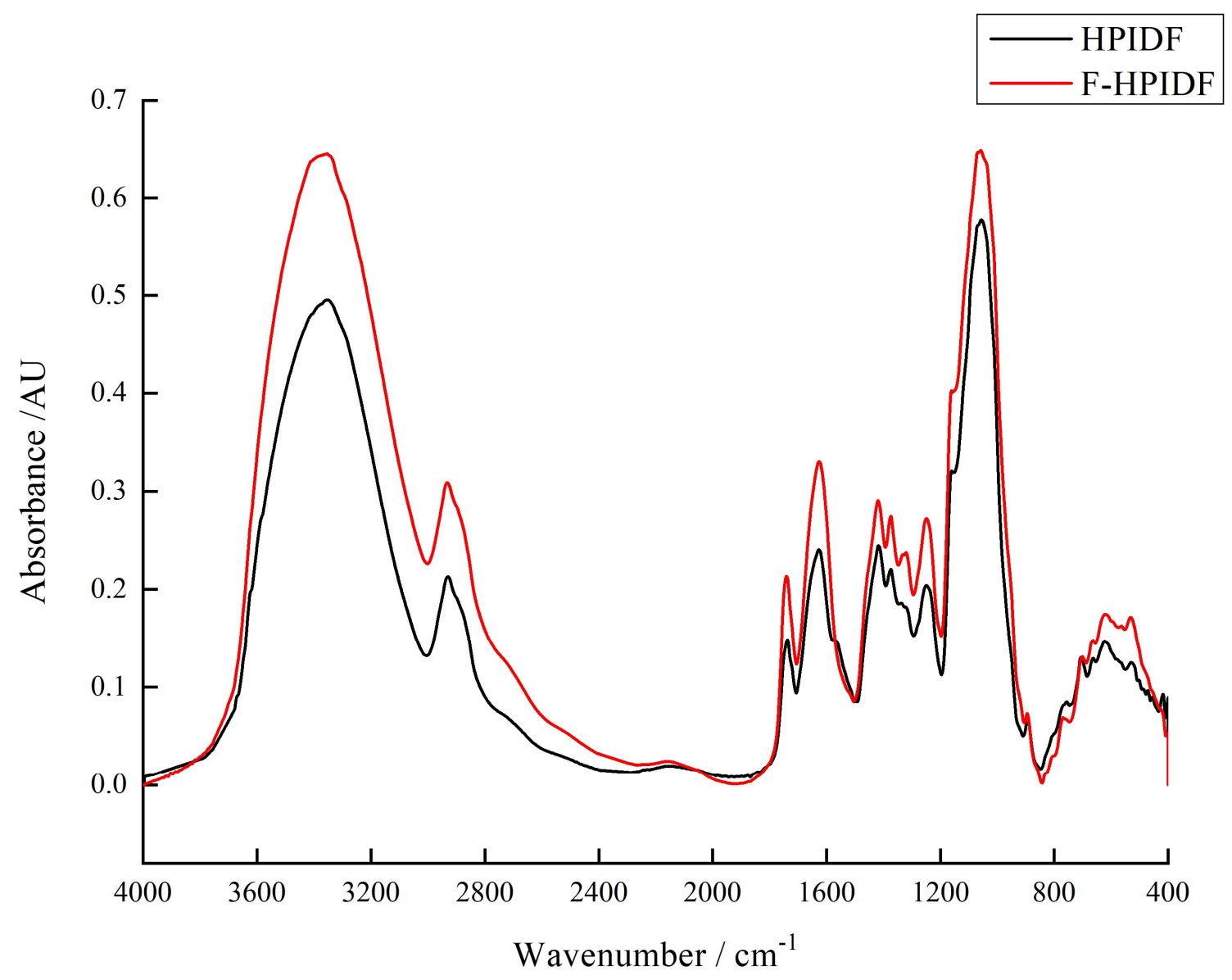

Figure 4. Fourier transform infrared spectrum (FTIR) of HPIDF/F-HPIDF. (Black: HPIDF; Red: F-HPIDF).

Although no differences were found in peak location, F-HPIDF had a markable characteristic in the FT-IR spectrum analysis. All peaks in F-HPIDF are higher than that in HPIDF, which means the fermentation increased the exposure of all functional groups. This result was consistent with the SEM results. The more complex the spatial structure, the greater the exposure of functional groups. This inference needs to be supported by the results of particle size and the specific surface area below.

To sum up, the fermentation might change the structure of HPIDF but did not change the composition, which would make the adsorption of F-HPIDF better than that of HPIDF, so that it may have better potential bioactivity in the colon. 


\subsubsection{Particle Size and Specific Surface Area}

Particle size and specific surface area of HPIDF/F-HPIDF are shown in Table 1, which both showed significant differences $(p<0.05)$. The smaller average particle size and the increase of specific surface area might lead to a higher adsorption capacity of harmful substances and metal ions. This result was in high agreement with the results of SEM and FTIR. These showed that the fermentation had made a great change in the structure of HPIDF. As for the composition, the analysis of monosaccharide composition of HPIDF, F-HPIDF, and hydrolysate was necessary.

Table 1. Particle size and specific surface area of HPIDF/F-HPIDF.

\begin{tabular}{cccccc}
\hline & $\mathbf{D}_{\mathbf{1 0}}(\boldsymbol{\mu m})$ & $\mathbf{D}_{\mathbf{2 5}}(\boldsymbol{\mu m})$ & $\mathbf{D}_{\mathbf{5 0}}(\boldsymbol{\mu m})$ & $\mathbf{D}_{\mathbf{7 5}}(\boldsymbol{\mu m})$ & ${\text { Specific Surface Area }\left(\mathbf{m}^{\mathbf{2}} / \mathbf{k g}\right)}$ \\
\hline HPIDF & $8.52 \pm 0.08^{\mathrm{a}}$ & $24.59 \pm 0.58^{\mathrm{a}}$ & $53.33 \pm 1.45^{\mathrm{a}}$ & $102.24 \pm 5.69^{\mathrm{a}}$ & $90.24 \pm 1.27^{\mathrm{a}}$ \\
F-HPIDF & $6.02 \pm 0.05^{\mathrm{b}}$ & $11.25 \pm 0.12^{\mathrm{b}}$ & $30.00 \pm 0.39^{\mathrm{b}}$ & $64.60 \pm 1.48^{\mathrm{b}}$ & $135.75 \pm 1.36^{\mathrm{b}}$ \\
\hline
\end{tabular}

Different lowercase letters indicate a significant difference $(p<0.05)$.

\subsection{The Monosaccharide Composition of HPIDF, F-HPIDF, and Hydrolysate}

The monosaccharide composition of HPIDF, F-HPIDF, and hydrolysate is shown in Figure 5. The main constituents of HPIDF are shown in Figure 5a, which are same as the previous result [16]. With the progress of colonic fermentation, the monosaccharide composition of HPIDF changed significantly. F-HPIDF (Figure $5 b$ ) consisted of a less content of galactose $(34.40 \%)$ and galacturonic acid $(11.47 \%)$, meanwhile a higher content of arabinose (27.49\%), rhamnose (5.32\%), glucose (6.86\%), and fucose $(3.91 \%)$ than HPIDF. This showed that galactose and galacturonic acid were used as the carbon source of bacteria in the colon during fermentation.

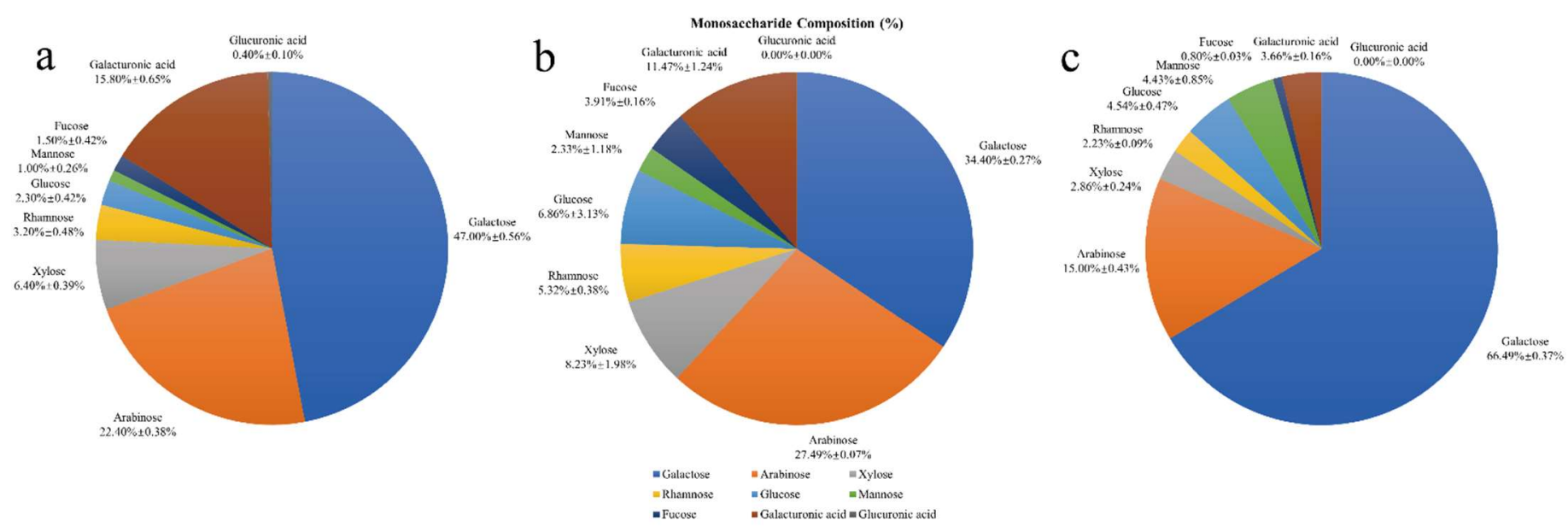

Figure 5. The monosaccharide composition of HPIDF, F-HPIDF, and hydrolysate. (a: HPIDF; b: F-HPIDF; c: Hydrolysate).

As for the hydrolysate (Figure 5c), galactose $(66.49 \%)$ and arabinose $(15.00 \%)$ were the main components. The largest component in the hydrolysate should be considered as the monosaccharide that constituted the main component of HPIDF. As know, monosaccharides that make up hemicelluloses are mainly glucose, xylose, mannose, arabinose, and galactose [29]. This result proved that HPIDF is a dietary fiber with hemicellulose as the core. Then, during colonic fermentation, a large amount of hemicellulose was decomposed to free monosaccharides, which is a typical fermentation mode of hemicellulose [30].

The colonic fermentation model of HPIDF with hemicellulose as the main part should be regarded as one of the important findings of this study, which could help us to carry out more accurate research on the metabolic model of colonic microorganisms using HPIDF. On this basis, the metabolic pathway of free monosaccharides in the colon can be studied to make sure if they had any potential functional value. Even the modification of HPIDF 
could be carried out based on the result, at least we can add modifiers to the functional groups of hemicellulose so that to make these components easier to release in the colon.

In this experiment, the microorganism used to ferment HPIDF was mainly Lactobacillus (genus level), and the main components of HPIDF were hemicellulose and lignin. The fermentation mode of hemicellulose by Lactobacillus is relatively clear. In short, it is a process of using hemicellulose as the carbon source to produce lactic acid in the colon [31,32]. An increase in lactic acid, as a precursor of propionic acid [33], results in an increase of shortchain fatty acid (SCFA). This phenomenon is beneficial to colon health and may even prevent colon cancer $[34,35]$. In contrast, the high level of lactic acid in the colon may also have adverse effects on intestinal health [36]. However, we believed that the lactic acid produced by dietary fiber fermentation should not pose this risk because they are ingested non-exogenously.

As the above process occurred, many new monosaccharides would appear in the colon, in which the composition was mainly galactose and arabinose. Galactose is a widely recognized functional monosaccharide with biological activities, such as being conducive to the appreciation of Bifidobacterium [37]. Galactose binding to lectin [38], a process that occurs in the colon before cancerization, proved that galactose plays an important role in intestinal health. Arabinose is also an intestinal prebiotic, which can prevent or even treat colitis by affecting the composition of intestinal flora directly [39]. In short, the monosaccharides produced by the fermentation of colonic flora would have a positive effect on intestinal health.

\subsection{The Adsorption Capacity of HPIDF/F-HPIDF}

\subsubsection{WHC, WSC, and OHC of HPIDF/F-HPIDF}

The WHC and WSC of HPIDF/F-HPIDF are shown in Figure 6a. Although the WHC and WSC of HPIDF are much higher than other IDFs [40,41], those of F-HPIDF $(19.17 \mathrm{~g} / \mathrm{g}$, $24.83 \mathrm{~mL} / \mathrm{g})$ were still higher than HPIDF $(p<0.01)$. Carboxyl $(-\mathrm{COOH})$ and hydroxyl $(-\mathrm{OH})$ are the common polar functional groups in IDFs. The larger specific surface area and smaller particle size represented more polar groups in contact with the environment. The excellent water absorption of F-HPIDF was consistent with the previous results of the structure changes.
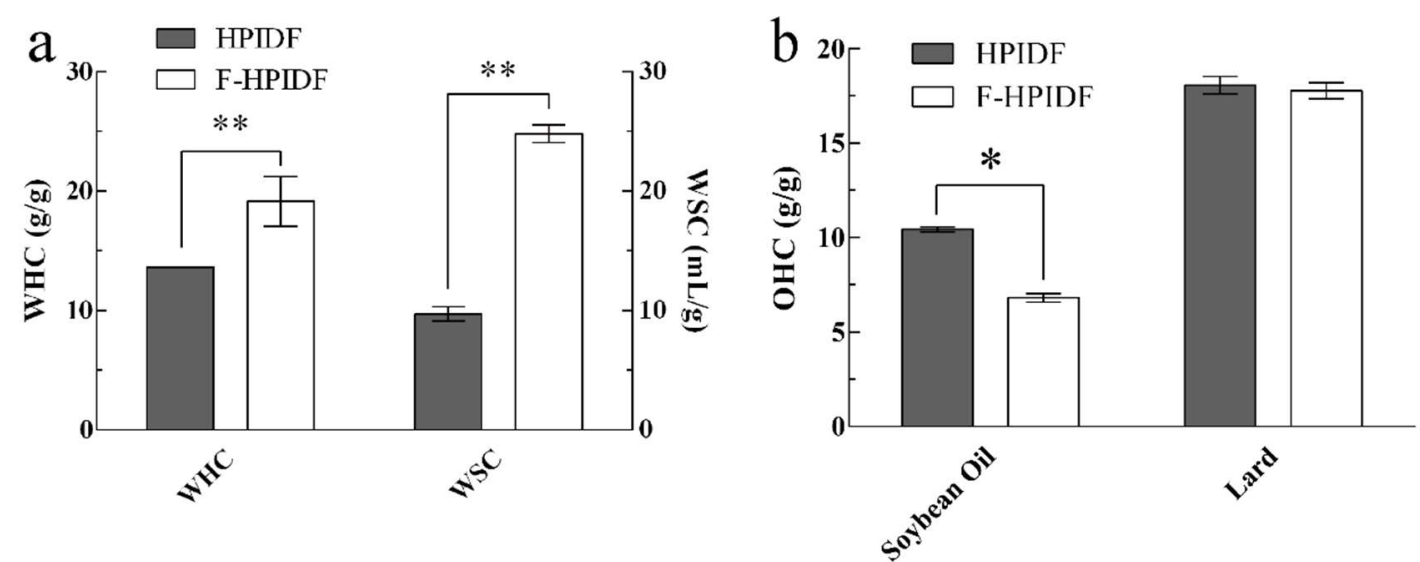

Figure 6. WHC, WSC and OHC of HPIDF/F-HPIDF. (a: WHC \& WSC; b: OHC; ${ }^{*} p<0.05 ;{ }^{* *}: p<0.01$ ).

The OHC of HPIDF/F-HPIDF is shown in Figure $6 b$. The mechanisms of dietary fiber to adsorb saturated and unsaturated oils are different. So, we chose soybean oil and lard to determine the different OHCs of HPIDF/F-HPIDF. The result shows that the OHC of F-HPIDF for unsaturated fat $(6.82 \mathrm{~g} / \mathrm{g})$ was lower than that of HPIDF $(p<0.05)$, however not different $(17.77 \mathrm{~g} / \mathrm{g})$ from that for saturated fat $(p>0.05)$. Common hydrophobic groups include $\mathrm{C}-\mathrm{H}$ stretching $\left(-\mathrm{CH}_{3}\right.$ or $\left.=\mathrm{CH}_{2}\right)$, ethers $(\mathrm{C}-\mathrm{O})$, etc. This just showed that the hydrophobic groups in HPIDF were exposed less with the progress of fermentation, which 
might be attributed to the decomposition of hemicellulose during the progress described in 3.3. Acetyl should be considered as the characteristic functional group of hemicellulose [42], the decomposition of hemicellulose might lead to the loss of acetyl, which could be the result of the decrease of OHC. In contrast, saturated fat (such as lard) does not contain unsaturated bonds, which leads to a weaker dependence on acetyl than saturated fat. To prevent excessive absorption of fat by the intestine, a higher $\mathrm{OHC}$ is desirable. According to the fermentation mode of HPIDF in this study, we may try to modify the non-hemicellulose components so that they will not be decomposed by the gut flora while maintaining a high content of hydrophobic groups.

\subsubsection{HMAC of HPIDF/F-HPIDF}

The adsorption capacity of HPIDF/F-HPIDF for metal ions is shown in Figure 7. On the whole, the adsorption capacities of F-HPIDF to four kinds of heavy metal were higher than that of HPIDF. The adsorption capacity of F-HPIDF for $\mathrm{Cd}^{2+}(1.82 \mu \mathrm{mol} / \mathrm{g})$ and $\mathrm{Pb}^{2+}$ $(1.91 \mu \mathrm{mol} / \mathrm{g})$ was similar; meanwhile, the adsorption capacity of $\mathrm{Cu}^{2+}(0.68 \mu \mathrm{mol} / \mathrm{g})$ was still the lowest. The HMAC of dietary fiber was directly related to its particle size and specific surface area [43], which led to the phenomenon in this study. This result was consistent with the structural analysis results.

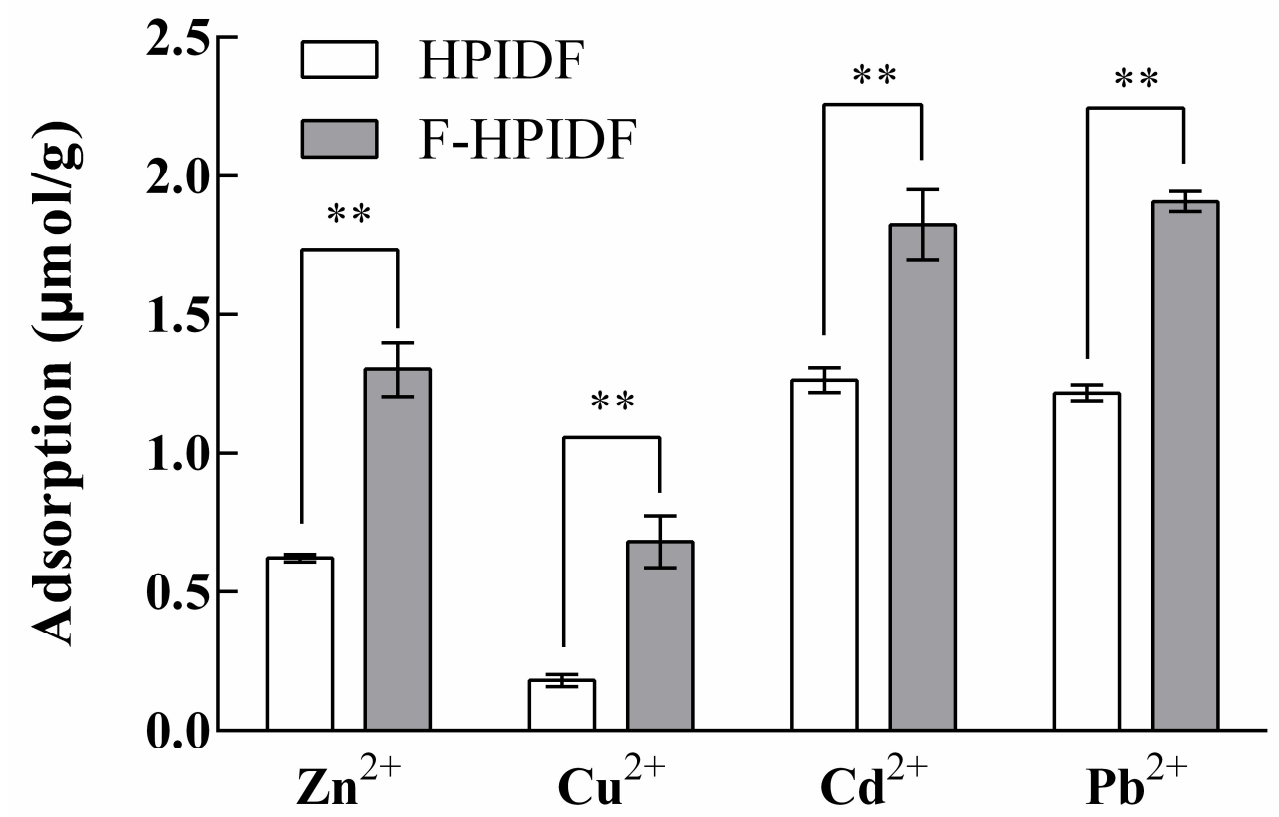

Figure 7. Heavy metal-adsorption capacity of HPIDF/F-HPIDF. (**: $p<0.01)$.

The excessive intake of heavy metals was not only harmful to intestinal health but also might damage multiple organs $[44,45]$. With the progress of fermentation, the HMAC of HPIDF gradually became stronger, which was a very good situation for the digestive system. Heavy metal ions were difficult to enter the blood and would be excreted via feces. In short, the fermentation process of HPIDF in the colon may prevent the body from ingesting excessive heavy metals.

\subsubsection{Potentially Harmful Substances-Adsorption Capacity of HPIDF/F-HPIDF}

We used glucose-adsorption capacity, cholesterol-adsorption capacity, sodium cholateadsorption capacity, acrylamide-adsorption capacity, and nitrite-adsorption capacity to determine the adsorption function to potentially harmful substances of HPIDF and FHPIDF. The results are shown in Figure 8. 

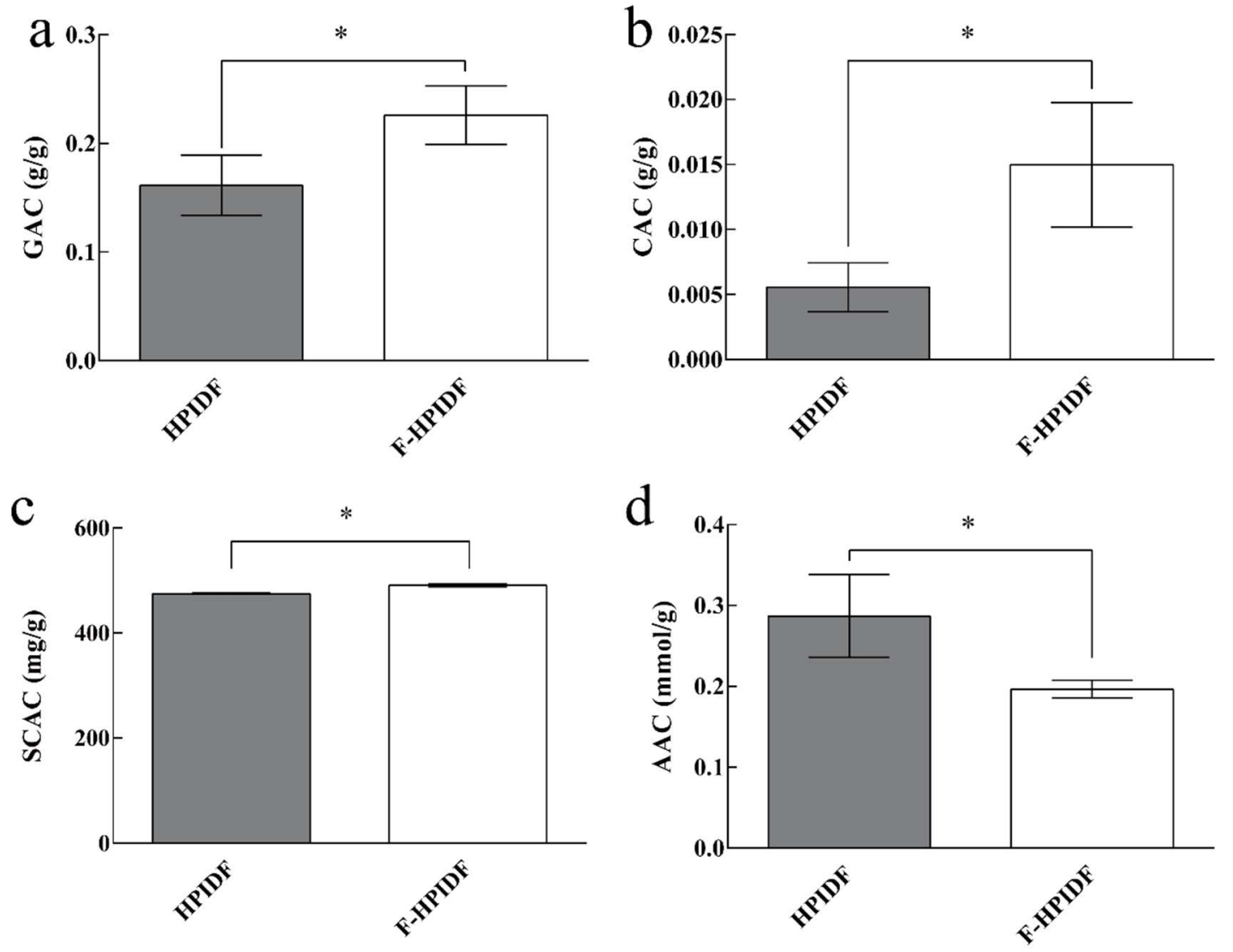

Figure 8. Potentially harmful substances-adsorption capacity of HPIDF/F-HPIDF. (a: GAC; b: CAC; c: SCAC; d: AAC; *: $p<0.05)$.

First, the adsorption capacity of HPIDF/F-HPIDF to nitrite was not shown in the results. According to previous research, HPIDF showed nitrite-adsorption capacity only in the gastric juice [16]. The same situation occurred in this study, we even did not find that F-HPIDF had a detectable nitrite-adsorption capacity. Therefore, the result was not shown in the figure. In short, whether it was fermented or not, HPIDF had no nitrite-adsorption capacity in the colon.

Normal amount of glucose is an important energy source for the body, but excessive glucose will cause a burden, which should be called a substance that may affect the health of the body. The GAC of F-HPIDF (Figure $8 a$ ) portrayed a better trend $(0.23 \mathrm{~g} / \mathrm{g}$ ), suggesting that F-HPIDF may prevent glucose from being over absorbed in the intestine. The GAC of HPIDF is the result of multiple adsorption mechanisms [46]. Therefore, the higher available surface, smaller particle size, and more functional group exposure of F-HPIDF lead to better glucose adsorption than HPIDF. As one of the main places for the body to absorb glucose, the intestine could be prevented from absorbing due to the presence of F-HPIDF, especially the glucose produced by the decomposition of digestive juice.

As shown in Figure 8b, F-HPIDF (14.80 mg/g) exhibited a high cholesterol-adsorption capacity than HPIDF (5.58 mg/g). After F-HPIDF was mixed with cholesterol, the absorption in the colon of cholesterol could be controlled by reducing the solubility of cholesterol [47]. This mode of action was similar to GAC.

The SCAC of HPIDF/F-HPIDF is shown in Figure 8c. F-HPIDF $(0.49 \mathrm{~g} / \mathrm{g})$ exhibited a small increase in SCAC than HPIDF $(0.47 \mathrm{~g} / \mathrm{g})$. As a substance produced by bile acids, sodium cholate may lead to intestinal inflammation and even apoptosis [48,49]. A good sodium cholate-adsorption capacity may be a potentially beneficial effect on intestine health Compared with our previous research [16], the sodium cholate-adsorption capacity in this experiment had a great improvement. We speculated that the reason may be the difference 
between the adsorption time. In the early stage, when we carried out an adsorption test in the digestive solution, $4 \mathrm{~h}$ was used for adsorption, which was much shorter than $14 \mathrm{~h}$. In this experiment, to distinguish the differences in adsorption capacity before and after fermentation, we selected a long time to simulate the retention of dietary fiber in the intestine [50]. This showed that the adsorption of sodium cholate was still going on after $4 \mathrm{~h}$. Then, the cholate adsorption kinetics of F-HPIDF may be also an object worthy of further study.

The acrylamide-adsorption capacity of F-HPIDF $(0.20 \mathrm{mmol} / \mathrm{g})$ showed a little decrease than HPIDF (Figure 8d). We had emphasized that the AAC of okara-HPIDF did not change with the gastroenteric environments. Therefore, AAC should only be related to the structure of the dietary fiber. The acrylamide-adsorption capacity on plant DF is generally weak, meanwhile mainly depended on physical adsorption [51]. Then we speculated that the decrease of AAC of F-HPIDF still came from the degradation of hemicellulose, although the specific surface area of F-HPIDF increased with the progress of fermentation. Hemicellulose was used as an adsorption material or matrix of acrylamide in previous studies [52,53].

In summary, the adsorption capacity of HPIDF to potentially harmful substances changed significantly after fermentation by colonic flora. The differences of F-HPIDF and HPIDF in properties were due to the changes in their structure during fermentation in vivo. Therefore, this process depended on the changes caused by the specific metabolic mechanism of colonic microorganisms.

\section{Conclusions}

In this study, the changes in the structure (SEM, FT-IR, XRD, particle size, specific area, and monosaccharide composition) and the adsorption capacity (WHC, WSC, OHC, heavy metal-adsorption capacity, and harmful substances-adsorption capacity) were analyzed to measure the changes between F-HPIDF and HPIDF. The results suggested that after being fermented by colonic microorganisms, the structure and properties of okara-HPIDF changed greatly. These findings provide a more accurate analysis of HPIDF after entering the digestive system. Meanwhile, the excellent adsorption and physicochemical properties caused by structural changes are beneficial to colon health. The intake of HPIDF might increase the number of beneficial monosaccharides in the colon, which might improve the composition of SCFA and have a beneficial impact on the body. This study also speculated that HPIDF may be modified to enhance its biological activity after its fermentation mode had been identified. The above all proved that HPIDF may have more utilization value.

Author Contributions: B.L.: conceptualization, software, writing-original draft; Y.W.: visualization, software, writing—original draft; X.Z.: writing—review \& editing; Y.C.: methodology; H.F.: investigation; T.L.: methodology; J.H.: visualization; Y.L.: investigation; H.Y.: funding acquisition, project administration; L.J.: funding acquisition, project administration. All authors have read and agreed to the published version of the manuscript.

Funding: This research was funded by China Agriculture Research System of MOF and MARA, grant number CARS-04; The Excellent Youth Project of Natural Science Foundation of Heilongjiang Province, grant number YQ2021C023; Major Science and Technology Innovation Projects in Shandong Province, grant number 2019JZZY010722.

Institutional Review Board Statement: The study was conducted according to the guidelines of the Declaration of Helsinki, and approved by the Ethics Committee of Laboratory Animal Welfare and Ethics Committee of Northeast Agricultural University.

Informed Consent Statement: Not applicable.

Data Availability Statement: Raw data can be provided by the corresponding author on request.

Acknowledgments: The authors acknowledge Shanghai Personal Biotechnology Co., Ltd. for their support to the $16 \mathrm{~S}$ rDNA Sequencing.

Conflicts of Interest: No conflict of interest. 


\section{References}

1. Hua, M.; Lu, J.; Qu, D.; Liu, C.; Zhang, L.; Li, S.; Chen, J.; Sun, Y. Structure, physicochemical properties and adsorption function of insoluble dietary fiber from ginseng residue: A potential functional ingredient. Food Chem. 2019, 286, 522-529. [CrossRef]

2. Zhao, G.; Zhang, R.; Dong, L.; Huang, F.; Tang, X.; Wei, Z.; Zhang, M. Particle size of insoluble dietary fiber from rice bran affects its phenolic profile, bioaccessibility and functional properties. LWT 2018, 87, 450-456. [CrossRef]

3. Meng, X.; Liu, F.; Xiao, Y.; Cao, J.; Wang, M.; Duan, X. Alterations in physicochemical and functional properties of buckwheat straw insoluble dietary fiber by alkaline hydrogen peroxide treatment. Food Chem. X 2019, 3, 100029. [CrossRef]

4. Hino, S.; Takemura, N.; Sonoyama, K.; Morita, A.; Kawagishi, H.; Aoe, S.; Morita, T. Small intestinal goblet cell proliferation induced by ingestion of soluble and insoluble dietary fiber is characterized by an increase in sialylated mucins in rats. J. Nutr. 2012, 142, 1429-1436. [CrossRef]

5. McIntosh, G.; Jorgensen, L.; Royle, P. The potential of an insoluble dietary fiber-rich source from barley to protect from DMHinduced intestinal tumors in rats. Nutr. Cancer 1993, 19, 213-221. [CrossRef] [PubMed]

6. Chen, T.; Chen, D.; Tian, G.; Zheng, P.; Mao, X.; Yu, J.; He, J.; Huang, Z.; Luo, Y.; Luo, J. Effects of soluble and insoluble dietary fiber supplementation on growth performance, nutrient digestibility, intestinal microbe and barrier function in weaning piglet. Anim. Feed. Sci. Technol. 2020, 260, 114335. [CrossRef]

7. Wilberts, B.L.; Arruda, P.H.; Kinyon, J.M.; Frana, T.S.; Wang, C.; Magstadt, D.R.; Madson, D.M.; Patience, J.F.; Burrough, E.R. Investigation of the impact of increased dietary insoluble fiber through the feeding of distillers dried grains with solubles (DDGS) on the incidence and severity of Brachyspira-associated colitis in pigs. PLoS ONE 2014, 9, e114741. [CrossRef] [PubMed]

8. Miles, J.P.; Zou, J.; Kumar, M.-V.; Pellizzon, M.; Ulman, E.; Ricci, M.; Gewirtz, A.T.; Chassaing, B. Supplementation of low-and high-fat diets with fermentable fiber exacerbates severity of DSS-induced acute colitis. Inflamm. Bowel Dis. 2017, 23, 1133-1143. [CrossRef] [PubMed]

9. Singh, V.; San Yeoh, B.; Walker, R.E.; Xiao, X.; Saha, P.; Golonka, R.M.; Cai, J.; Bretin, A.C.A.; Cheng, X.; Liu, Q. Microbiota fermentation-NLRP3 axis shapes the impact of dietary fibres on intestinal inflammation. Gut 2019, 68, 1801-1812. [CrossRef] [PubMed]

10. Armstrong, H.; Mander, I.; Zhang, Z.; Armstrong, D.; Wine, E. Not All Fibers Are Born Equal; Variable Response to Dietary Fiber Subtypes in IBD. Front. Pediatr. 2021, 8, 924. [CrossRef]

11. Vong, W.C.; Liu, S.-Q. Biovalorisation of okara (soybean residue) for food and nutrition. Trends Food Sci. Technol. 2016, 52, 139-147. [CrossRef]

12. Lu, F.; Liu, Y.; Li, B. Okara dietary fiber and hypoglycemic effect of okara foods. Bioact. Carbohydr. Diet. Fibre 2013, 2, 126-132. [CrossRef]

13. Jiménez-Escrig, A.; Tenorio, M.D.; Espinosa-Martos, I.; Rupérez, P. Health-promoting effects of a dietary fiber concentrate from the soybean byproduct okara in rats. J. Agric. Food Chem. 2008, 56, 7495-7501. [CrossRef]

14. Fan, X.; Chang, H.; Lin, Y.; Zhao, X.; Zhang, A.; Li, S.; Feng, Z.; Chen, X. Effects of ultrasound-assisted enzyme hydrolysis on the microstructure and physicochemical properties of okara fibers. Ultrason. Sonochem. 2020, 69, 105247. [CrossRef] [PubMed]

15. Lazarin, R.A.; Falcão, H.G.; Ida, E.I.; Berteli, M.N.; Kurozawa, L.E. Rotating-Pulsed Fluidized Bed Drying of Okara: Evaluation of Process Kinetic and Nutritive Properties of Dried Product. Food Bioprocess Technol. 2020, 13, 1611-1620. [CrossRef]

16. Bo, L.; Huan, W.; Swallah, M.S.; Hongling, F.; Yue, S.; Zengwang, G.; Xiaohong, T.; Yang, L.; Hansong, Y.; Lianzhou, J. Structure, Properties and Potential Bioactivities of High-purity Insoluble Fibre from Soybean Dregs (Okara). Food Chem. 2021, $364,130402$.

17. Wang, S.; Sun, W.; Swallah, M.S.; Amin, K.; Lyu, B.; Fan, H.; Zhang, Z.; Yu, H. Preparation and characterization of soybean insoluble dietary fiber and its prebiotic effect on dyslipidemia and hepatic steatosis in high fat-fed C57BL/6J mice. Food Funct. 2021, 12, 8760-8773. [CrossRef] [PubMed]

18. Wang, B.; Yu, H.; He, Y.; Wen, L.; Gu, J.; Wang, X.; Miao, X.; Qiu, G.; Wang, H. Effect of soybean insoluble dietary fiber on prevention of obesity in high-fat diet fed mice via regulation of the gut microbiota. Food Funct. 2021, 12, 7923-7937. [CrossRef]

19. Gaddum, J.H. Hawley's Condensed Chemical Dictionary; United States Pharmacopeia: Rockville, MD, USA, 2007.

20. Wu, C.; Teng, F.; McClements, D.J.; Zhang, S.; Li, Y.; Wang, Z. Effect of cavitation jet processing on the physicochemical properties and structural characteristics of okara dietary fiber. Food Res. Int. 2020, 134, 109251. [CrossRef] [PubMed]

21. Zhang, X.; Yu, L.; Bi, H.; Li, X.; Ni, W.; Han, H.; Li, N.; Wang, B.; Zhou, Y.; Tai, G. Total fractionation and characterization of the water-soluble polysaccharides isolated from Panax ginseng CA Meyer. Carbohydr. Polym. 2009, 77, 544-552. [CrossRef]

22. Zhang, W.; Zeng, G.; Pan, Y.; Chen, W.; Huang, W.; Chen, H.; Li, Y. Properties of soluble dietary fiber-polysaccharide from papaya peel obtained through alkaline or ultrasound-assisted alkaline extraction. Carbohydr. Polym. 2017, 172, 102-112. [CrossRef] [PubMed]

23. Xie, F.; Wang, Y.; Wu, J.; Wang, Z. Functional properties and morphological characters of soluble dietary fibers in different edible parts of Angelica keiskei. J. Food Sci. 2016, 81, C2189-C2198. [CrossRef] [PubMed]

24. Lkhagva, E.; Chung, H.-J.; Hong, J.; Tang, W.H.W.; Lee, S.-I.; Hong, S.-T.; Lee, S. The regional diversity of gut microbiome along the GI tract of male C57BL/6 mice. BMC Microbiol. 2021, 21, 44. [CrossRef] [PubMed]

25. Mohtar, S.S.; Busu, T.N.Z.T.M.; Noor, A.M.M.; Shaari, N.; Mat, H. An ionic liquid treatment and fractionation of cellulose, hemicellulose and lignin from oil palm empty fruit bunch. Carbohydr. Polym. 2017, 166, 291-299. [CrossRef] [PubMed]

26. Alba, K.; Macnaughtan, W.; Laws, A.; Foster, T.J.; Campbell, G.; Kontogiorgos, V. Fractionation and characterisation of dietary fibre from blackcurrant pomace. Food Hydrocoll. 2018, 81, 398-408. [CrossRef] 
27. Ullah, I.; Yin, T.; Xiong, S.; Zhang, J.; Din, Z.-u.; Zhang, M. Structural characteristics and physicochemical properties of okara (soybean residue) insoluble dietary fiber modified by high-energy wet media milling. LWT-Food Sci. Technol. 2017, 82, 15-22. [CrossRef]

28. Sharma, V.; Smolin, J.; Nayak, J.; Ayala, J.E.; Scott, D.A.; Peterson, S.N.; Freeze, H.H. Mannose alters gut microbiome, prevents diet-induced obesity, and improves host metabolism. Cell Rep. 2018, 24, 3087-3098. [CrossRef]

29. Mudgil, D.; Barak, S. Composition, properties and health benefits of indigestible carbohydrate polymers as dietary fiber: A review. Int. J. Biol. Macromol. 2013, 61, 1-6. [CrossRef]

30. Reddy, N.R.; Palmer, J.K.; Pierson, M.D.; Bothast, R.J. Wheat straw hemicelluloses: Composition and fermentation by human colon Bacteroides. J. Agric. Food Chem. 1983, 31, 1308-1313. [CrossRef]

31. Garde, A.; Jonsson, G.; Schmidt, A.S.; Ahring, B.K. Lactic acid production from wheat straw hemicellulose hydrolysate by Lactobacillus pentosus and Lactobacillus brevis. Bioresour. Technol. 2002, 81, 217-223. [CrossRef]

32. Moldes, A.; Torrado, A.; Converti, A.; Dominguez, J. Complete bioconversion of hemicellulosic sugars from agricultural residues into lactic acid by Lactobacillus pentosus. Appl. Biochem. Biotechnol. 2006, 135, 219-227. [CrossRef]

33. Duncan, S.H.; Barcenilla, A.; Stewart, C.S.; Pryde, S.E.; Flint, H.J. Acetate utilization and butyryl coenzyme A (CoA): Acetate-CoA transferase in butyrate-producing bacteria from the human large intestine. Appl. Environ. Microbiol. 2002, 68, 5186-5190. [CrossRef]

34. Rafter, J.J. The role of lactic acid bacteria in colon cancer prevention. Scand. J. Gastroenterol. 1995, 30, 497-502. [CrossRef] [PubMed]

35. Singh, J.; Rivenson, A.; Tomita, M.; Shimamura, S.; Ishibashi, N.; Reddy, B.S. Bifidobacterium longum, a lactic acid-producing intestinal bacterium inhibits colon cancer and modulates the intermediate biomarkers of colon carcinogenesis. Carcinogenesis 1997, 18, 833-841. [CrossRef]

36. Lin, J.; Nafday, S.M.; Chauvin, S.N.; Magid, M.S.; Pabbatireddy, S.; Holzman, I.R.; Babyatsky, M.W. Variable effects of short chain fatty acids and lactic acid in inducing intestinal mucosal injury in newborn rats. J. Pediatric Gastroenterol. Nutr. 2002, 35, 545-550. [CrossRef] [PubMed]

37. Torres, D.P.; Gonçalves, M.d.P.F.; Teixeira, J.A.; Rodrigues, L.R. Galacto-oligosaccharides: Production, properties, applications, and significance as prebiotics. Compr. Rev. Food Sci. Food Saf. 2010, 9, 438-454. [CrossRef]

38. Evans, R.C.; Fear, S.; Ashby, D.; Hackett, A.; Williams, E.; Van Der Vliet, M.; Dunstan, F.D.; Rhodes, J.M. Diet and colorectal cancer: An investigation of the lectin/galactose hypothesis. Gastroenterology 2002, 122, 1784-1792. [CrossRef]

39. Li, Y.; Pan, H.; Liu, J.; Li, T.; Liu, S.; Shi, W.; Sun, C.; Fan, M.; Xue, L.; Wang, Y. 1-Arabinose inhibits colitis by modulating gut microbiota in mice. J. Agric. Food Chem. 2019, 67, 13299-13306. [CrossRef]

40. Luo, X.; Wang, Q.; Zheng, B.; Lin, L.; Chen, B.; Zheng, Y.; Xiao, J. Hydration properties and binding capacities of dietary fibers from bamboo shoot shell and its hypolipidemic effects in mice. Food Chem. Toxicol. 2017, 109, 1003-1009. [CrossRef] [PubMed]

41. Wen, Y.; Niu, M.; Zhang, B.; Zhao, S.; Xiong, S. Structural characteristics and functional properties of rice bran dietary fiber modified by enzymatic and enzyme-micronization treatments. LWT 2017, 75, 344-351. [CrossRef]

42. Wang, S.; Ru, B.; Lin, H.; Sun, W. Pyrolysis behaviors of four O-acetyl-preserved hemicelluloses isolated from hardwoods and softwoods. Fuel 2015, 150, 243-251. [CrossRef]

43. Kachenpukdee, N.; Santerre, C.R.; Ferruzzi, M.G.; Oonsivilai, R. Modified Dietary Fiber from Cassava Pulp and Assessment of Mercury Bioaccessibility and Intestinal Uptake Using an In Vitro Digestion/Caco-2 Model System. J. Food Sci. 2016, 81, T1854-T1863. [CrossRef] [PubMed]

44. Zhang, Y.; Huo, X.; Lu, X.; Zeng, Z.; Faas, M.M.; Xu, X. Exposure to multiple heavy metals associate with aberrant immune homeostasis and inflammatory activation in preschool children. Chemosphere 2020, 257, 127257. [CrossRef] [PubMed]

45. Ma, S.; Ren, B.; Diao, Z.; Chen, Y.; Qiao, Q.; Liu, X. Physicochemical properties and intestinal protective effect of ultra-micro ground insoluble dietary fibre from carrot pomace. Food Funct. 2016, 7, 3902-3909. [CrossRef]

46. Chen, J.; Zhao, Q.; Wang, L.; Zha, S.; Zhang, L.; Zhao, B. Physicochemical and functional properties of dietary fiber from maca (Lepidium meyenii Walp.) liquor residue. Carbohydr. Polym. 2015, 132, 509-512. [CrossRef]

47. Yao, S.-L.; Xu, Y.; Zhang, Y.-Y.; Lu, Y.-H. Black rice and anthocyanins induce inhibition of cholesterol absorption in vitro. Food Funct. 2013, 4, 1602-1608. [CrossRef]

48. Morita, S.; Ikeda, Y.; Tsuji, T.; Terada, T. Molecular mechanisms for protection of hepatocytes against bile salt cytotoxicity. Chem. Pharm. Bull. 2019, 67, 333-340. [CrossRef]

49. Labbé, A.; Ganopolsky, J.G.; Martoni, C.J.; Prakash, S.; Jones, M.L. Bacterial bile metabolising gene abundance in Crohn's, ulcerative colitis and type 2 diabetes metagenomes. PLoS ONE 2014, 9, e115175. [CrossRef]

50. Tabernero, M.; Venema, K.; Maathuis, A.J.; Saura-Calixto, F.D. Metabolite production during in vitro colonic fermentation of dietary fiber: Analysis and comparison of two European diets. J. Agric. Food Chem. 2011, 59, 8968-8975. [CrossRef]

51. Zhao, B.; Jiang, H.; Lin, Z.; Xu, S.; Xie, J.; Zhang, A. Preparation of acrylamide/acrylic acid cellulose hydrogels for the adsorption of heavy metal ions. Carbohydr. Polym. 2019, 224, 115022. [CrossRef] [PubMed]

52. Ferrari, E.; Ranucci, E.; Edlund, U.; Albertsson, A.C. Design of renewable poly (amidoamine)/hemicellulose hydrogels for heavy metal adsorption. J. Appl. Polym. Sci. 2015, 132. [CrossRef]

53. Kundu, D.; Mondal, S.K.; Banerjee, T. Development of $\beta$-cyclodextrin-cellulose/hemicellulose-based hydrogels for the removal of Cd (II) and Ni (II): Synthesis, kinetics, and adsorption aspects. J. Chem. Eng. Data 2019, 64, 2601-2617. [CrossRef] 